\title{
Fácies orgânica: conceitos, métodos e estudos de casos na indústria do petróleo
}

\author{
Taíssa Rêgo Menezes ${ }^{1}$, João Graciano Mendonça Filho², Carla Viviane Araujo ${ }^{1}$, \\ Igor Viegas Alves F. de Souza ${ }^{1} \&$ Joalice de Oliveira Mendonça ${ }^{2}$
}

\begin{abstract}
Resumo O conceito de fácies orgânica, bem como as definições e significado das diferentes fácies tornaram-se uma ferramenta muito importante na exploração de petróleo. A aplicação deste conceito é otimizada quando se faz a integração das técnicas de microscopia e geoquímicas para o estudo do querogênio contido em rochas sedimentares. Para tal, é empregada a análise de Palinofácies associada à Geoquímica Orgânica. A palinofácies compreende o estudo integrado de todos os aspectos das assembléias de componentes do querogênio: identificação dos componentes particulados individuais, determinação das proporções relativas e absolutas e do estado de preservação dos mesmos. A correlação entre os dados de palinofácies e geoquímica orgânica fornecem modelos de fácies orgânica, com informações tanto paleoambientais, quanto relativas ao potencial gerador de hidrocarbonetos.
\end{abstract}

Palavras-Chaves: Fácies Orgânica, Palinofácies, Geoquímica Orgânica, Exploração de Petróleo.

\begin{abstract}
Organic facies applied to petroleum exploration. The concept of organic facies, as well as the definitions and means of the different facies became a very important tool to petroleum exploration. The application of this concept is the best way to integrate microscopy and geochemical techniques to study kerogen contained in sedimentary rocks. Thus, palynofacies analysis and bulk geochemical methods are used to characterize the total particulate organic matter. Palynofacies analysis involves the integrated study of all aspects of the kerogen assemblage: identification of the individual particulate components, assessment of their absolute and relative proportions and preservation states. The correlation between palynofacies and geochemical data provides the organic facies models that point out the depositional environmental conditions and hydrocarbon source rock potential.
\end{abstract}

Keywords: Organic Facies, Palynofacies, Organic Geochemistry, Petroleum Exploration.

INTRODUÇÃ̃O A caracterização de rochas geradoras de hidrocarbonetos é uma ferramenta essencial para a avaliação dos riscos exploratórios, uma vez que a ocorrência de intervalos ricos em matéria orgânica é um pré-requisito básico para formação de acumulações de óleo ou gás. De acordo com Huc (1990), o estudo das rochas geradoras e a distribuição das fácies orgânicas associadas a elas, gera uma estratégica avaliação de bacias sedimentares com potencial petrolífero.

A utilização e a interpretação dos resultados analíticos de geoquímica orgânica compreende uma das etapas mais importantes para o sucesso da exploração petrolífera. Estes dados possibilitarão o posicionamento no tempo e no espaço da ocorrência de uma determinada fácies potencialmente geradora de hidrocarbonetos. Aliado a este mapeamento, o conhecimento de sistemas deposicionais, petrofísica, geofísica e geotectônica irão traduzir, através da modelagem de sistemas petrolíferos, o comportamento de sucessões sedimentares no que diz respeito: à história de soterramento, ao timing de geração e quantidade de hidrocarbonetos gerados, à composição do petróleo, à cinética do tipo de querogênio, à eficiência de expulsão de hidrocarbonetos, bem como a obtenção de informações sobre as propriedades da fração orgânica e sua interação com a fração mineral (e.g. Dow 1977, Jones 1978, Tissot \& Welte 1984, Huc 1990, Waples 1994, Demaison \& Huizinga 1991, Gonçalves et al. 1997, Magoon \& Dow 2000, Rudkiewicz et al. 2000, Penteado \& Behar 2000, Souto Filho et al. 2000, Trindade \& Penteado 2004).

Além disso, nos últimos trinta anos houve um significativo aumento de trabalhos referentes às interpretações de paleoambientes deposicionais utilizando dados das variações do conteúdo orgânico (e. g. Didyk et al. 1978, Batten 1982a, Jones 1987, Tyson 1987, Jacobson 1991, Gorin \& Steffen 1991, Tyson 1995, Batten 1996, Turnau \& Racki 1999, Baudin et al. 1999, Stasiuk 1999, Mendonça Filho 1999, Al-Almeri 2001, Schiǿler et al. 2002, Oboh-Ikuenobe et al. 2005, Zavattieri et al. 2008).

FÁCIES ORGÂNICA - CONCEITOS Os geocientistas observam as variações laterais e verticais de uma dada fácies orgânica tanto em "escala de bacia", quanto em "escala de lâmina", dependendo dos objetivos do trabalho e dos parâmetros utilizados para a sua defini- 
ção. Dentro de uma visão paleoecológica e paleoclimática, uma fácies orgânica pode identificar pequenos e grandes ciclos relacionados a eventos transgressivosregressivos. Contudo, a sua caracterização, também está relacionada ao paleoambiente deposicional, e a deposição de unidades estratigráficas geradoras de petróleo. Desta forma, a aplicação deste conceito é ampla e diversos autores consideram a inserção deste termo na literatura como o reconhecimento de uma indispensável ferramenta exploratória.

Muitos autores têm utilizado o termo fácies orgânica como sinônimo de fácies de querogênio, baseada em dados químicos, ou palinofácies ou fácies da associação de macerais, baseadas em dados petrográficos (Peters \& Cassa 1994).

Pode-se afirmar que a origem deste conceito recai claramente na forte atuação dos geólogos do carvão no final do século XIX e início do século XX, que foram os primeiros a reconhecer os tipos de matéria orgânica (macerais) que ocorrem em uma determinada camada de carvão, e assim relacionar a origem biológica deste depósito.

Na década de 70, Rogers \& Koons (1971) utilizaram os termos "fácies orgânica marinha" e "fácies orgânica continental" em sedimentos recentes do Golfo do México somente com base na distribuição de hidrocarbonetos $\mathrm{C}_{15+}$. Jones \& Edison (1979) reportaram que o principal problema, à frente de todos os cientistas que trabalhavam no campo de avaliação rochas geradoras, seria a escolha das técnicas analíticas que gerassem os dados necessários e suficientes. A partir daí, houve o aumento da integração de métodos de microscopia e geoquímica orgânica resultando no conceito de "Fácies Orgânica".

Quadros (1975) implantou na Petrobras as técnicas de microscopia para investigação da matéria orgânica em rochas sedimentares voltadas para Geoquímica Orgânica e adota os termos "Organopalinologia" e "Organopalinofácies".

Cornford (1979) utilizou o termo, sem discutir o conceito, apenas para comparar os métodos de estudo da matéria orgânica e inter-relacionar as interpretações. Posteriormente, Cornford et al.(1980) sintetizaram o conjunto de parâmetros de petrografia orgânica e geoquímica que caracterizam uma associação de sedimentos como "Organofácies".

Uma definição formal foi proposta por Jones \& Demaison (1980, 1982), onde uma "fácies orgânica consiste em uma subdivisão mapeável de uma determinada unidade estratigráfica sendo distinguida pelas características dos constituintes orgânicos, sem considerar os aspectos da fração inorgânica dos sedimentos".

Rogers (1980) foi o primeiro a caracterizar uma fácies orgânica baseando-se no tipo e na origem da matéria orgânica e no paleoambiente deposicional.

Segundo Peters et al. (1981), uma fácies orgânica sedimentar é determinada pelo tipo de organismo precursor, pelo paleoambiente deposicional e pelas condições da diagênese inicial da matéria orgânica. Este conceito é também refletido na definição de Powell (1987) sobre o controle deposicional na composição da matéria orgânica de rochas potencialmente geradoras de hidrocarbonetos, composição esta que depende da natureza da biomassa primária (algálica, bacteriana ou de vegetais superiores), da extensão do retrabalhamento bacteriano da matéria orgânica durante a deposição, da litologia da rocha geradora e da composição química águas no paleoambiente deposicional (salinidade, $\mathrm{pH}$, alcalinidade e oxigenação).

No clássico trabalho de Jones (1987), o autor define sete fácies orgânicas com base no critério químico e, em menor extensão, nos dados óticos. Essas fácies orgânicas podem ser determinadas para cada amostra, para grupos de amostras ou para unidades estratigráficas completas e os parâmetros utilizados são os de intervalos sedimentares imaturos, nos quais o poder refletor da vitrinita é de aproximadamente $0,5 \% \mathrm{VR}$.

De acordo com Pasley (1991), a definição de fácies orgânica apresentada por Jones é a mais apropriada devido às similaridades das fácies orgânicas com unidades estratigráficas distinguidas pela composição de sua matéria orgânica constituinte. Pasley integra os dados de petrografia orgânica e de geoquímica orgânica no conceito da estratigrafia de seqüência não só para melhorar o entendimento das ocorrências de rochas geradoras de petróleo, mas também para utilizar como ferramenta de predição.

Segundo Tyson (1995), o conceito de fácies orgânica pode ser definido como um "grupo de sedimentos contendo uma assembléia distinta de constituintes orgânicos que podem ser reconhecidos por microscopia ou estar associado com uma composição organogeoquímica característica".

\section{MÉTODOS DE DETERMINAÇÃO DE FÁCIES \\ ORGÂNICA Comumente, um dos critérios mais di-} fundidos para a caracterização da faciologia orgânica é a correlação de análises geoquímicas com resultados de análises microscópicas (petrografia orgânica e palinofácies), pois de acordo com o modelo de Jones \& Demaison $(1980,1982)$, a utilização desse conceito pelos geólogos exploracionistas está baseada nos seguintes fatores: (a) A matéria orgânica sedimentar é constituída de vários tipos de componentes orgânicos que podem ser discriminados por técnicas de microscopia e geoquímica; (b) Os diversos tipos de matéria orgânica podem gerar diferentes tipos e quantidades de óleo e gás; (c) Os mesmos tipos de matéria orgânica, e consequentemente os produtos por eles gerados (óleo e gás), podem se estender lateralmente por milhares de quilômetros quadrados e verticalmente por milhares de metros; (d) A distribuição de uma fácies orgânica não é homogênea, porém esta é determinada pela origem dos precursores biológicos e pelo regime de oxigênio do ambiente deposicional; (e) Fácies orgânicas podem ser mapeadas e extrapoladas; (f) Estudos de faciologia orgânica auxiliam no entendimento e na predição de jazidas de óleo é gás. 
Outro aspecto relevante para observação da matéria orgânica é o comportamento diante das alterações antes do soterramento (antes da transformação em querogênio): cada componente orgânico individual reage de maneira diferente aos processos de biodegradação, abrasão física, mudanças químicas relacionadas ao Eh e pH da coluna d'água e dos sedimentos.

Contudo, as alterações mais importantes a serem levadas em consideração no mapeamento de fácies orgânica são as mudanças decorrentes do intemperismo e do estágio de maturação, pois os parâmetros geoquímicos e microscópicos são afetados por estes processos. Ao mesmo tempo, o resultado obtido deste mapeamento deve refletir tanto a composição dos constituintes orgânicos originais, quanto às mudanças sofridas pós-soterramento, para que a avaliação de uma bacia sedimentar, com potencial petrolífero, esteja correta.

Fácies Orgânicas de Jones (1987) As sete fácies orgânicas definidas por Jones (1987) foram caracterizadas com base nos seguintes parâmetros: tipo de querogênio identificado através das técnicas de análise elementar (C, H e O); carbono orgânico total (COT); pirólise Rock-Eval e petrografia orgânica.

A combinação destas técnicas está fundamentada no princípio de que o tipo de querogênio reflete o potencial gerador de hidrocarbonetos, e a distribuição do querogênio é controlada por fatores biológicos e geológicos que condicionam a produção, preservação e acumulação de matéria orgânica (Jones \& Demaison 1982, Jacobson 1991) e que as variações na faciologia podem ser gradacionais.

As sete fácies orgânicas foram designadas por letras (A, AB, B, BC, C, CD e D) e a diferença básica entre elas é a capacidade de geração de petróleo por unidade de carbono orgânico total em rochas imaturas (poder refletor da vitrinita em torno de 0,5\%; Tab. 1). No entanto, de acordo com Durand (1980), o parâmetro que se presta para a distinção de diferentes fácies é a razão $\mathrm{H} / \mathrm{C}$ do querogênio proveniente da análise elementar (C, H e O) (Fig. 1).

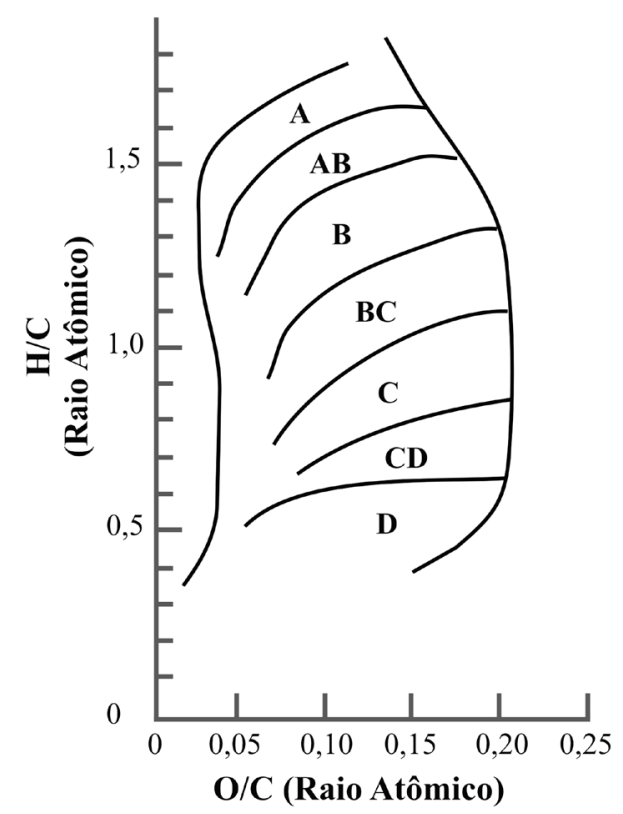

Figura 1 - Diagrama van Krevelen com as fácies orgânicas de Jones (1987).

Tabela 1 - Características geoquímicas e microscópicas das fácies orgânicas $A-D$. Os valores de H/C correspondem seções sedimentares imaturas (0,5\% VR) (Jones, 1987).

\begin{tabular}{l|c|c|c|c}
\hline \multirow{2}{*}{$\begin{array}{c}\text { Fácies } \\
\text { Orgânica }\end{array}$} & $\begin{array}{c}\text { H/C } \\
(\mathbf{0 , 5 \%} \mathbf{V R})\end{array}$ & \multicolumn{2}{|c|}{$\begin{array}{c}\text { Parâmetros da pirólise } \\
\text { Rock-Eval }\end{array}$} & \multirow{2}{*}{ Matéria orgânica dominante } \\
\cline { 3 - 4 } & & $\mathbf{I H}$ & $\mathbf{I O}$ & Algálica; MOA \\
\hline $\mathrm{A}$ & $\geq 1,45$ & $>850$ & $10-30$ & MOA + minoria terrestre \\
\hline $\mathrm{AB}$ & $1,35-1,45$ & $650-850$ & $20-50$ & MOA + terrestre \\
\hline $\mathrm{B}$ & $1,15-1,35$ & $400-650$ & $30-80$ & Mistura + M.O. oxidada \\
\hline $\mathrm{BC}$ & $0,95-1,15$ & $200-400$ & $40-80$ & Terrestre + M.O. oxidada \\
\hline $\mathrm{C}$ & $0,75-0,95$ & $125-250$ & $50-150$ & M.O. oxidada; retrabalhada \\
\hline $\mathrm{CD}$ & $0,60-0,70$ & $50-125$ & $40-150+$ & M.O. oxidada + retrabalhada \\
\hline $\mathrm{D}$ & $\leq 0,6$ & $<50$ & $20-200+$ & \\
\hline
\end{tabular}

$\mathrm{IH}=$ Índice de Hidrogênio (mg HC/gCOT); IO = Índice de Oxigênio $\left(\mathrm{mg} \mathrm{CO}_{2} / \mathrm{gCOT}\right)$;

$\% \mathrm{VR}=$ Poder refletor da vitrinita; $\mathrm{MOA}=$ matéria orgânica amorfa; M.O. = matéria orgânica 
Os parâmetros abaixo relacionados precederam o conceito de faciologia orgânica, tal como descrito acima tendo sido incorporados nos estudos dessa natureza.

PARAMMETRO - TIPO DE QUEROGÊNIO IDENTIFICADO ATRAVÉS DAS TÉCNICAS DE ANÁLISE ELE$\operatorname{MENTAR}(C, H E O) \quad$ D. W. van Krevelen apresentou o melhor resumo sobre as propriedades fisico-químicas dos carvões com o trabalho Coal, Typology, Physics, Chemistry, Constitution (1961, e reimpresso em 1981), onde foi proposto um diagrama com os resultados das análises elementares de $\mathrm{H}, \mathrm{C}$ e $\mathrm{O}$, através das razões H/C e O/C. Desde então, o "diagrama de van Krevelen" tornou-se uma inestimável ferramenta para sintetizar a relação entre as propriedades físico-químicas e petrográficas do querogênio (Durand 2003).

PARÂMETRO - PIRÓLISE ROCK-EVAL Do mesmo modo, observa-se na tabela 1 , a correlação dos valores da razão H/C com os valores de Índice de Hidrogênio e Índice de Oxigênio (parâmetros obtidos com a pirólise Rock-Eval). Devido ao sucesso da técnica de pirólise Rock-Eval desenvolvido por Espitalié et al. (1977) no Instituo Francês de Petróleo, os resultados derivados desta análise rotineira, substituem os resultados de H/C e O/C na identificação de diferentes fácies orgânica.

PARÂMETRO - PETROGRAFIA ORGÂNICA Os resultados de petrografia orgânica utilizam a identificação visual dos componentes orgânicos através das técnicas de microscopia de luz branca transmitida e luz azul incidente (fluorescência), onde os três grupos principais do querogênio são identificados: Matéria Orgânica Lenhosa, Matéria Orgânica Amorfa e Matéria Orgânica Liptinítica (Durand 1980).

A criação da Petrografia Orgânica deve-se à conjunção da Palinologia com a Petrografia do Carvão. Na década de 60, a Palinologia tornou-se importante para a Geoquímica Orgânica com os trabalhos de Combaz na Companhia Francesa de Petróleo (1964), de Gutjar na Shell (1966) e de Correia no Instituto Francês de Petróleo (1967). Paralelamente, a atuação dos petrográfos do carvão e pioneiros na petrografia orgânica (e.g. M. Teichmüller, B. Alpern, P. van Gijzel, N.H. Bostick e H. Jacob) foi decisiva para a Petrografia Orgânica tornarse um método complementar e indispensável na análise da matéria orgânica sedimentar. Somado a isso, o International Committee for Coal Petrography (ICCP) criou a comissão relacionada aos estudos da matéria orgânica dispersa e, posteriormente houve a criação em 1984 de uma segunda sociedade, Society for Organic Petrology (Durand 2003).

O PAPEL DA PALINOFÁCIES NA CARACTERIZAÇÃO DE FÁCIES ORGÂNICA A avaliação da fração orgânica particulada (querogênio) em rochas sedimentares utilizando técnicas de microscopia permite que a análise visual seja realizada tanto em amostras de concentrado de querogênio, através da análise de palinofácies (Tyson 1984, 1987, Oboh 1992, Batten 1996, Araujo et al. 1998, Follows \& Tyson 1998, Al-Ameri et al. 2001, Mendonça Filho 1999, Carvalho 2001, Menezes 2002, Spigolon 2003, Oboh-Ikuenobe et al. 2005, Iemini et al. 2007, Souza 2007), quanto em amostras de rocha total através da petrografia orgânica (Stasiuk 1996, Chow et al 1995, Stasiuk 1999, Stasiuk \& Fowler 2004).

O conceito de palinofácies foi introduzido por Combaz (1964) para descrever a assembléia total de constituintes da matéria orgânica contida em um sedimento após a remoção da matriz sedimentar (mineral) pela acidificação com ácido clorídrico $(\mathrm{HCl})$ e fluorídrico (HF). Inicialmente, Combaz determinou as proporções dos fragmentos orgânicos isolados (esporos, grãos de pólen, fragmentos lenhosos, etc) de rochas sedimentares e denominou estes resultados de palinofácies.

Hughes \& Moody-Stuart (1967) propuseram o termo fácies palinológicas na mesma percepção de palinofácies de Combaz (1964) para descrever todos os constituintes orgânicos após remoção da matriz mineral e, a partir da identificação do querogênio, direcionaram os resultados palinológicos para estudos de paleobotânica.

Os trabalhos de J.D. Batten (e.g. 1981, 1982a, 1982b), aplicaram o conceito palinofácies não só para estudos paleoambientais e bioestratigráficos, mas também para as respostas do potencial gerador e maturação térmica em rochas sedimentares.

Habib (1982) considera esta técnica um aspecto particular de fácies orgânica podendo, assim, ser considerada como "fácies orgânica definida palinológicamente".

O conceito moderno de "Fácies Orgânica", às vezes, é tratado como sinônimo de "Palinofácies" pelos palinólogos e geoquímicos, visto que é difícil demarcar o limite entre a palinofácies e a faciologia orgânica. Assim, nenhuma técnica isolada pode fornecer todas as respostas para o estudo e a explicação dos modelos de fácies orgânica, pois variações significativas de palinofácies podem ocorrer em uma dada fácies orgânica definida com parâmetros organogeoquímicos. Além disso, os diversos parâmetros gerados permitem uma análise mais detalhada das variações no ambiente sedimentar e da matéria orgânica original.

Segundo Tyson (1995), a análise de palinofácies compreende o estudo de ambientes deposicionais e do potencial de rochas geradoras de hidrocarbonetos com base no conteúdo palinológico presente nas rochas sedimentares. Sendo assim, a Palinofácies pode ser definida como "um corpo de sedimento contendo uma assembléia distinta de matéria orgânica palinológica que reflete um grupo especifico de condições ambientais, podendo ser associada com um potencial de geração de hidrocarbonetos característico".

Uma das grandes vantagens da aplicação da análise de palinofácies é o caráter interdisciplinar, o qual associa palinologia, sedimentologia, estratigrafia e geoquímica orgânica, além da possibilidade de ser 
utilizada em estudos relacionados a outras áreas das Geociências.

$\mathrm{Na}$ análise de palinofácies o objetivo é integrar todos os aspectos dos componentes da matéria orgânica como: (a) identificar os componentes palinológicos individuais; (b) classificar os grupos e subgrupos do querogênio; (c) determinar as proporções relativas, atentando particularmente ao seu tamanho, forma e estado de preservação.
Para tal, é realizado um exame qualitativo e quantitativo em lâminas de concentrado de querogênio, utilizando-se técnicas de microscopia de luz branca transmitida e luz azul/ultravioleta incidente (fluorescência). A identificação da matéria orgânica particulada obedece à classificação geral proposta por Tyson (1995) Mendonça Filho (1999) e Mendonça Filho et al. (2002) (Tabs. 2, 3 e 4 e Figs. 2 e 3) e a análise consiste na contagem de 300 a 500 componentes orgânicos por

Tabela 2 - Classificação da matéria orgânica particulada (baseado em Tyson 1995, Mendonça Filho 1999, Mendonça Filho et al. 2002).

\begin{tabular}{l|c|l}
\hline \multirow{2}{*}{ GRUPO } & SUBGRUPO & DESCRIÇÃO \\
\hline & $\begin{array}{c}\text { "M.O.A." } \\
\text { Material orgânico derivado } \\
\text { de ataque microbiológico. }\end{array}$ & $\begin{array}{l}\text { Material não estruturado e com formato variado; cor: } \\
\text { amarela-laranja-vermelho; laranja-marrom; cinza, algumas } \\
\text { vezes com inclusões de palinomorfos, fitoclasto, pirita. } \\
\text { Pode exibir ou não colorações de fluorescência. }\end{array}$ \\
$\begin{array}{c}\text { M A T É R I A } \\
\text { A M O R F A }\end{array}$ & $\begin{array}{c}\text { Resina } \\
\text { Derivada de vegetais superiores } \\
\text { terrestres de florestas tropicais } \\
\text { e subtropicais. }\end{array}$ & $\begin{array}{l}\text { Partícula não estruturada, hialina, usualmente arredondada, } \\
\text { homogênea, fluorescente ou não-fluorescente. }\end{array}$ \\
\hline
\end{tabular}

Tabela 3 - Classificação do Grupo Fitoclasto (baseado em Tyson 1995, Mendonça Filho 1999, Mendonça Filho et al. 2002).

\begin{tabular}{|c|c|c|c|c|c|}
\hline GRUPO & \multicolumn{4}{|c|}{ SUBGRUPO } & DESCRIÇÃO \\
\hline \multirow{9}{*}{$\begin{array}{l}0 \\
E \\
0 \\
4 \\
= \\
ن \\
0 \\
= \\
= \\
=\end{array}$} & \multirow{9}{*}{ 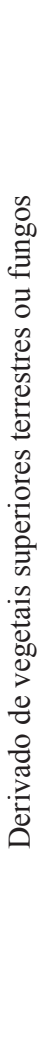 } & \multirow{3}{*}{ Opaco } & \multicolumn{2}{|c|}{ Equidimensional } & $\begin{array}{l}\text { Partícula de cor preta de forma quadrática, sem bioestruturas } \\
\text { internas. }\end{array}$ \\
\hline & & & \multicolumn{2}{|c|}{ Alongado } & $\begin{array}{l}\text { Partícula de cor preta de forma alongada, comprimento três vezes } \\
\text { maior que a largura, usualmente não apresenta estrutura interna, } \\
\text { porém, os de forma alongada podem, ocasionalmente, apresentar } \\
\text { perfurações. }\end{array}$ \\
\hline & & & \multicolumn{2}{|c|}{ Corroído } & Partícula de cor preta com contornos difusos e irregulares. \\
\hline & & \multirow{5}{*}{$\begin{array}{l}\text { Não- } \\
\text { Opaco }\end{array}$} & \multirow{4}{*}{$\begin{array}{c}\text { Não-degradado } \\
\text { contorno nítido, pode } \\
\text { ser levemente irregular, } \\
\text { ou mesmo, lascado. } \\
\text { ou } \\
\text { Degradado } \\
\text { contorno irregular e } \\
\text { difuso, lascado. } \\
\text { ou } \\
\text { Pseudoamorfo } \\
\text { Pode exibir coloração de } \\
\text { fluorescência contorno } \\
\text { difuso, algum aspecto de } \\
\text { MOA. }\end{array}$} & $\begin{array}{l}\text { Não- } \\
\text { bioestruturado }\end{array}$ & Partícula de cor marrom não-bioestruturada. \\
\hline & & & & Bioestruturado & $\begin{array}{l}\text { Partícula de cor marrom bioestruturada: estriado, listrado, bandado, } \\
\text { perfurado. }\end{array}$ \\
\hline & & & & Cutícula & $\begin{array}{l}\text { Partículas cor amarelo-pálido a marrom claro, delgadas, com } \\
\text { estrutura celular, em alguns casos, com estômatos visíveis. }\end{array}$ \\
\hline & & & & Membrana & $\begin{array}{l}\text { Partículas de cor amarelo-pálido, comumente transparentes, } \\
\text { sem estrutura celular. }\end{array}$ \\
\hline & & & \multicolumn{2}{|c|}{ Hifas de Fungo } & $\begin{array}{l}\text { Elemento filamentoso individual que forma o micélio da fase } \\
\text { vegetativa dos fungos. }\end{array}$ \\
\hline & & $\begin{array}{l}\text { Opaco } \\
\text { ou } \\
\text { Não- } \\
\text { Opaco }\end{array}$ & Esclereídeo & \multicolumn{2}{|c|}{$\begin{array}{l}\text { Células que formam o tecido esclerenquimático, com parede secundária espessada e } \\
\text { impregnadas de lignina. Encontradas em diferentes partes do vegetal (raiz, caule e folha) } \\
\text { e têm a função de sustentação e resistência. }\end{array}$} \\
\hline
\end{tabular}


Tabela 4 - Classificação do Grupo Palinomorfo (baseado em Tyson 1995, Mendonça Filho 1999, Mendonça Filho et al. 2002).

\begin{tabular}{|c|c|c|c|c|}
\hline GRUPO & \multicolumn{3}{|c|}{ SUBGRUPO } & DESCRIÇÃO \\
\hline \multirow{10}{*}{$\begin{array}{l}0 \\
1 \\
\simeq \\
0 \\
\Sigma \\
0 \\
0 \\
Z \\
= \\
= \\
\varangle \\
\sim\end{array}$} & \multirow{2}{*}{ 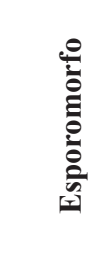 } & Esporo & $\begin{array}{l}\text { Palinomorfo terrestre } \\
\text { produzido por pteridó- } \\
\text { fitas, briófitas e fungos }\end{array}$ & $\begin{array}{l}\text { Possui forma triangular ou circular, apresentando a marca } \\
\text { trilete ("Y") ou monolete. Ornamentação variada. } \\
\text { * Podem ocorrem como mássulas, aglomerados e tétrades. }\end{array}$ \\
\hline & & Grão de Pólen & $\begin{array}{l}\text { Palinomorfo terrestre } \\
\text { produzido por gimnos- } \\
\text { permas e angiospermas }\end{array}$ & $\begin{array}{l}\text { Possui morfologia complexa asimples, usualmente esférico } \\
\text { a subesférico; ornamentação variada,pode apresentar } \\
\text { aberturas. * Podem ocorrem como aglomerados e tétrades. }\end{array}$ \\
\hline & \multirow{2}{*}{ 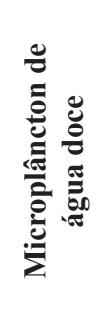 } & Botryococcus & \multirow[b]{2}{*}{ Algas Chlorococcales } & $\begin{array}{l}\text { Colônias globulares irregulares; tamanho } 30 \text { a } 2000 \mu \mathrm{m} \text {, } \\
\text { algumas vezes com vários lóbulos; laranja-marrom. } \\
\text { Ordoviciano-Recente }\end{array}$ \\
\hline & & Pediastrum & & $\begin{array}{l}\text { Algas verdes coloniais, radialmente simétricas; tamanho } \\
30-200 \mu \mathrm{m} \text { em diâmetro com dois chifres no anel mais } \\
\text { externo das células. Células internas podem ser de forma } \\
\text { irregular com espaços entre elas ou compactadas. Jurássico } \\
\text { (?)-Recente }\end{array}$ \\
\hline & \multirow{3}{*}{ 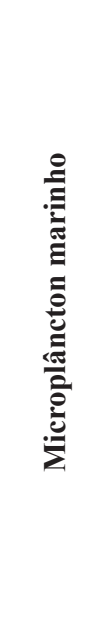 } & Dinocistos & $\begin{array}{l}\text { Restos de cistos produ- } \\
\text { zidos durante a parte } \\
\text { sexual do ciclo de vida. }\end{array}$ & $\begin{array}{l}\text { Principal característica é a paratabulação que divide a teca } \\
\text { do cisto em placas retangulares ou poligonais separadas por } \\
\text { suturas. Três morfologias principais: proximados, cavados } \\
\text { e corados.Muitas vezes com uma abertura (arqueólipo) } \\
\text { através da qual ocorre o encistamento. } \\
\text { Triássico-Recente. Existem espécies atuais de água doce. }\end{array}$ \\
\hline & & Prasinófitas & $\begin{array}{l}\text { Microfóssies produzidos } \\
\text { por pequenas algas qua- } \\
\text { driflageladas }\end{array}$ & $\begin{array}{l}\text { Maioria, como Tasmanites, são esféricas; diâmetro } 50 \text { à } \\
2000 \mu \mathrm{m} \text {. Pré-Cambriano-Recente. Existem espécies atuais } \\
\text { de água doce. }\end{array}$ \\
\hline & & Acritarcos & $\begin{array}{l}\text { Cistos fossilizados, } \\
\text { unicelulares de parede } \\
\text { orgânica. Afinidade ta- } \\
\text { xonômica incerta. }\end{array}$ & $\begin{array}{l}\text { Eucariontes de pequena dimensão ( } 5 \text { à } 150 \mu \mathrm{m} \text { ). Possui } \\
\text { simetria, forma, estrutura e tipo de desenvolvimento da } \\
\text { ornamentação bem variados. Surgiram no Pré-Cambriano, } \\
\text { com auge no Ordoviciano-Devoniano e quase extintos no } \\
\text { Permo-Carbonífero. No Meso-Cenozóico exibem baixa } \\
\text { diversidade. }\end{array}$ \\
\hline & \multirow{3}{*}{ 을 } & Palinoforaminífero & $\begin{array}{l}\text { Películainternaquitinosa } \\
\text { que reveste a carapaça } \\
\text { de foraminíferos }\end{array}$ & $\begin{array}{l}\text { Revestimento orgânico interno de testas de } \\
\text { microforaminíferos recuperados na preparação de amostras } \\
\text { para análises de palinofácies e palinologia. Coloração bege, } \\
\text { marrom claro a marrom escuro. Os principais morfogrupos } \\
\text { são baseados no arranjo das câmaras. }\end{array}$ \\
\hline & & Escolecodonte & $\begin{array}{l}\text { Elementos dispersos } \\
\text { do aparelho bucal de } \\
\text { anelídeos poliquetas }\end{array}$ & Composição: quitina. Ordoviciano inferior- Recente. \\
\hline & & Quitinizoário & $\begin{array}{l}\text { Vesículas em formato } \\
\text { de fracos ou garrafinhas } \\
\text { ocas, afinidade incerta }\end{array}$ & $\begin{array}{l}\text { Constituem um grupo extinto de organismos marinhos, } \\
\text { dotados de testas orgânicas de quitina ( } 30 \text { a } 2000 \mu \mathrm{m}) \text {. } \\
\text { Ordoviciano-Devoniano. }\end{array}$ \\
\hline O u tros & \multicolumn{4}{|c|}{ Ex: Spongiophyton, Zooclastos (Graptólitos, Ovos de copépoda) } \\
\hline
\end{tabular}

lâmina.

Esta análise requer procedimentos de preparação de amostras eficazes para o isolamento do querogênio, utilizando-se de métodos palinológicos padrões não-oxidativos. Oliveira et al. (2004 e 2006) desenvolveram novos métodos para uma maior recuperação de querogênio em seções sedimentares com teores de COT inferiores a $1 \%$ e para eliminar os efeitos de aditivos de perfuração de composição orgânica. Sendo assim, esta técnica pode ser aplicada na caracterização paleoambiental tanto de rochas geradoras, como de rochas reservatórios e de rochas selantes (Mendonça Filho et al. 2007).

As interpretações são baseadas na abundância relativa dos componentes orgânicos particulados. Cada componente individual está relacionado com a sua 

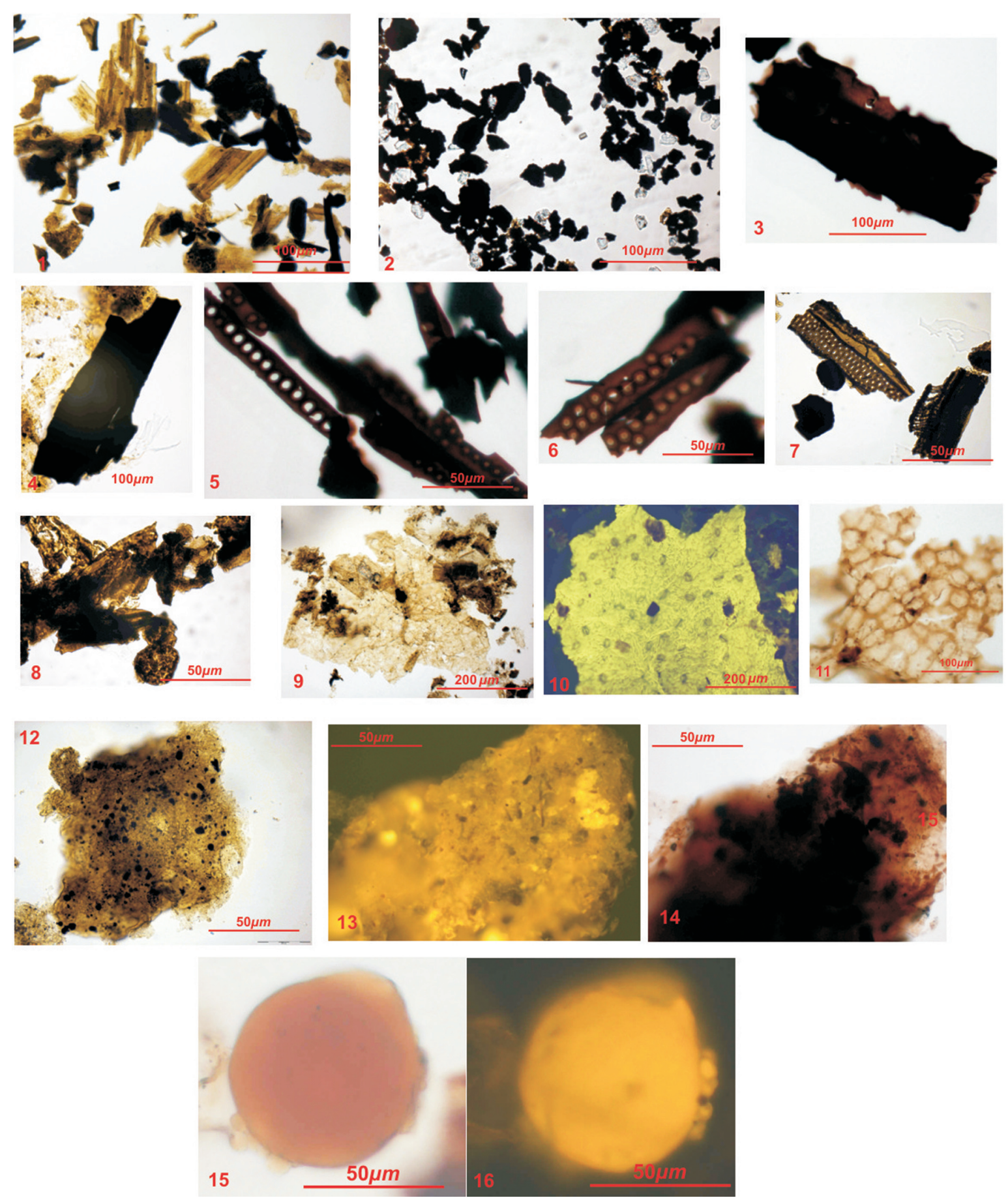

Figura 2 - Componentes Orgânicos Particulados. 1- Palinofácies rica em fitoclastos não-opacos; 2- Palinofácies rica em fitoclastos opacos; 3- Fitoclasto não-opaco não-degradado; 4- Fitoclasto opaco alongado; 5 e 7- Fitoclastos não-opacos bioestruturados; 8-Associação de palinofácies com fitoclastos não-opacos bioestruturados e não-bioestruturados; 9 e 11-Cutícula; 12 a 14- Matéria Orgânica Amorfa; 15 e 16- Produto secundário: Betume. Fotomicrografias: 1a 9, 11, 12, 14 e 15 sob Luz Branca Transmitida; 10, 12 e 16 - sob Luz Azul Incidente (Fluorescência).

origem biológica e com as condições de preservação. Adicionalmente, um constituinte orgânico se comporta como uma partícula sedimentar, ou seja, a tendência de distribuição de cada grupo ou subgrupo do querogênio está condicionada aos processos sedimentares que atuam no transporte e deposição da matéria orgânica sedimentar.
Diversos parâmetros são gerados para definir uma palinofácies, como, por exemplo, a covariância e as possíveis razões obtidas entre componentes orgânicos, Fi-COT (relação do conteúdo COT com a fração lenhosa) e o Índice de Preservação de Fitoclastos que expressa as tendências de degradação de partículas lenhosas. 


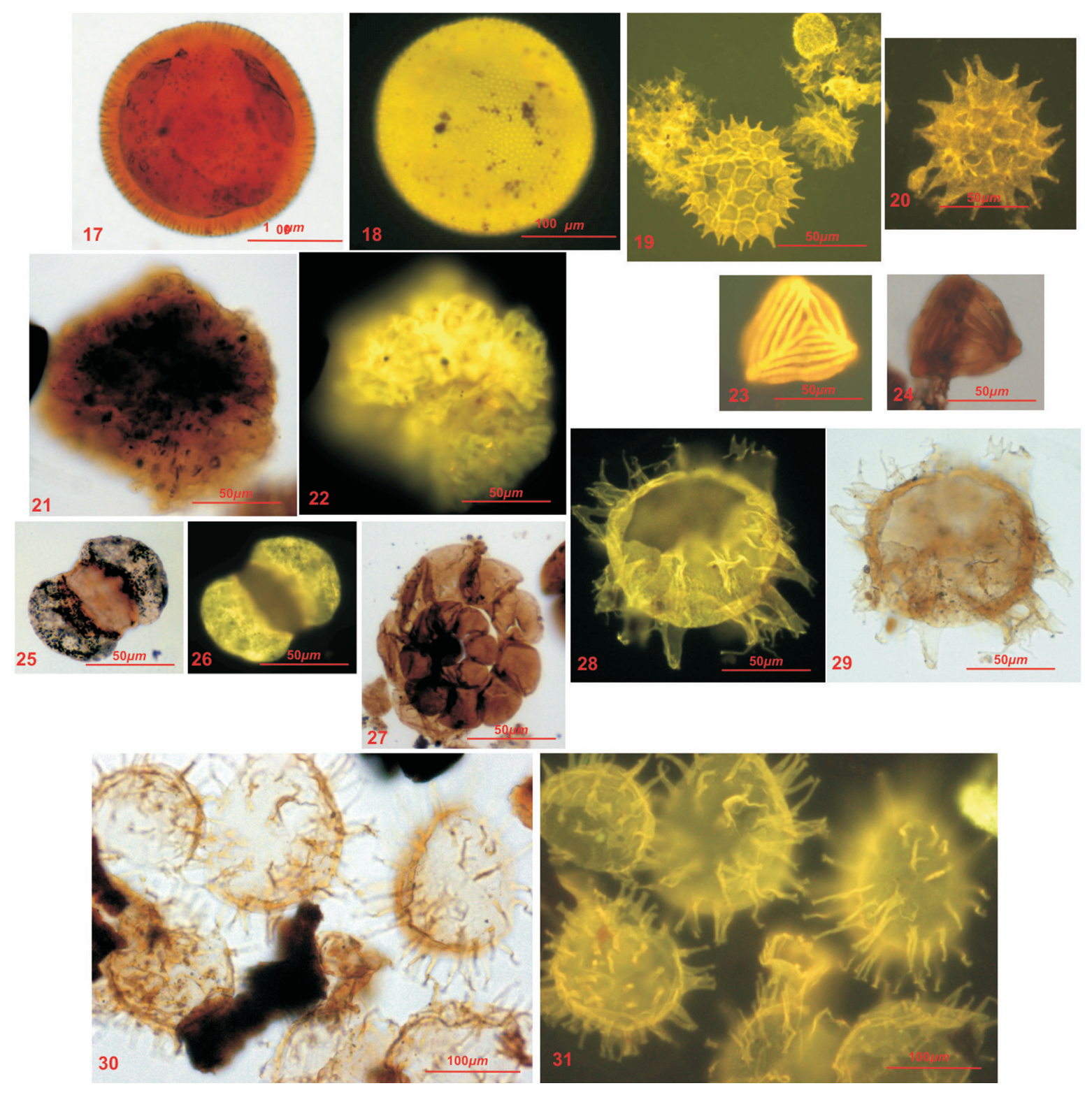

Figura 3 - Componentes Orgânicos Particulados. 17 e 18 - Alga Prasinophyta - gênero Tasmanites; 19 e 20 - Alga de água doce do gênero Pediastrum; 21 e 22 - Alga de água doce do gênero Botryococcus; 23 e 24 - Esporo trilete; 25 e 26 - Grão de pólen bissacado; 27 - Palinoforaminifero; 28 e 29 - Alga marinha - dinocisto do gênero Glaphyrocysta; 30 e 31 - Aglomerado de dinocistos - gênero Polysphaeridium. Fotomicrografias: 17, 21, 24, 25, 27, 29 e 30 - sob Luz Branca Transmitida; 18, 19, 20, 22, 23, 26, 28 e 31 - sob Luz Azul Incidente (Fluorescência).

Desta forma, a análise de palinofácies pode fornecer informações sobre: (a) Magnitude e locação de entrada de terrígenos (relação proximal-distal); (b) Características do paleoambiente (condições redox, tendências de elevação e rebaixamento do nível relativo do mar); (c) Distinção entre os diferentes paleoambientes deposicionais; (d) Potencial gerador de hidrocarbonetos das diferentes fácies orgânica; (e) Subdivisão de fácies sedimentares uniformes, especialmente folhelhos.

CORRELAÇÃO DA PALINOFÁCIES COM A GEOQUÍMICA ORGÂNICA As diferentes fácies orgânicas definidas por Jones têm sido descritas em ro- chas sedimentares de diversas idades, sendo que o critério químico é primeiramente usado para caracterizá-las e identificar os processos químicos, físicos e biológicos. Tuweni \& Tyson (1994) consideram que a combinação de COT e pirólise com análises de palinofácies se constitui num excelente modo de caracterização de fácies orgânica.

Tyson (1995) correlacionou os aspectos das faciologia sensu Jones (1987) com os parâmetros obtidos pela análise de palinofácies, e reuniu as sete fácies orgânica de Jones em três grupos baseados nas características de deposição da matéria orgânica (Tab. 5): (a) Fácies anóxica-disóxica (A, AB, B, BC); (b) Fácies 
Tabela 5 - Correlação da fácies orgânica de Jones (1987) e palinofácies de Tyson (1995) (modificada de Mendonça Filho 1999).

\begin{tabular}{|c|c|c|}
\hline $\begin{array}{c}\text { FÁCIES ORGÂNICA } \\
(0,5 \mathrm{VR} \%)\end{array}$ & DESCRIÇÃO & CARACTERÍSTICAS DE PALINOFÁCIES \\
\hline $\begin{array}{c}\mathbf{A} \\
\mathrm{IH}>850 \mathrm{mgHC} / \mathrm{gCOT} \\
\mathrm{COT} 5-20 \%\end{array}$ & $\begin{array}{l}\text { Rara; bem laminada; rica em conteúdo orgânico; } \\
\text { usualmente lacustre; anoxia persistente no fundo } \\
\text { da coluna d'água; aporte desprezível de matéria } \\
\text { orgânica terrestre. }\end{array}$ & $\begin{array}{l}\text { Matéria orgânica amorfa dominante; baixo conteúdo } \\
\text { de fitoclastos; razão opacos/não-opacos elevada; rica } \\
\text { em prasinófitas, se marinha, e Algas Chloroccocales, } \\
\text { se lacustre. }\end{array}$ \\
\hline $\begin{array}{c}\mathbf{A B} \\
\mathrm{IH}=650-850 \\
\mathrm{COT} 3-10 \%\end{array}$ & $\begin{array}{l}\text { Laminada; rica em conteúdo orgânica; matéria } \\
\text { orgânica quase que exclusivamente composta por } \\
\text { componentes derivados de algas e/ou bactérias; } \\
\text { anoxia persistente na coluna d'água. }\end{array}$ & $\begin{array}{l}\text { Matéria orgânica amorfa dominante; baixo conteúdo } \\
\text { de fitoclastos; razão opacos/não-opacos elevada; rica } \\
\text { em prasinófitas, se marinha, e Algas Chloroccocales, } \\
\text { se lacustre. }\end{array}$ \\
\hline $\begin{array}{c}\text { B } \\
\mathrm{IH}=400-650 \\
\text { COT } 3-10 \%\end{array}$ & $\begin{array}{l}\text { Laminada a acamadada; percentagem mais elevada } \\
\text { de matéria orgânica terrestre e residual que a fácies } \\
\mathrm{AB} \text {; freqüentemente ocorre uma anoxia flutuante no } \\
\text { fundo da coluna d'água; freqüentemente intercalada } \\
\text { com fácies menos ricas. }\end{array}$ & $\begin{array}{l}\text { Matéria orgânica amorfa dominante; baixo conteúdo } \\
\text { de fitoclastos; razão opacos/não-opacos elevada; rica } \\
\text { em prasinófitas, se marinha, e algas Chloroccocales, } \\
\text { se lacustre. }\end{array}$ \\
\hline $\begin{array}{c}\text { BC } \\
\mathrm{IH}=250-400 \\
\text { COT } 1-3 \%\end{array}$ & $\begin{array}{l}\text { Coluna d'água óxica; deposição rápida cria } \\
\text { anoxia pós-deposicional; matéria orgânica mista } \\
\text { parcialmente derivada de material terrestre / algálico } \\
\text { biodegradados. Bioturbação pode ser responsável } \\
\text { pela degradação da matéria orgânica marinha. }\end{array}$ & $\begin{array}{l}\text { Matéria orgânica amorfa moderada; conteúdo } \\
\text { moderado de fitoclastos; razão fitoclastos opacos/ } \\
\text { não-opacos usualmente baixa. }\end{array}$ \\
\hline $\begin{array}{c}\text { C } \\
\mathrm{IH}=125-250 \\
\mathrm{COT} 1-3 \%\end{array}$ & $\begin{array}{l}\text { Matéria orgânica dominada por matéria orgânica } \\
\text { terrestre degradada. Ocorre depósitos deltaicos, } \\
\text { em lamitos marinhos bioturbados e também em } \\
\text { turfeiras. }\end{array}$ & $\begin{array}{l}\text { Matéria orgânica amorfa ausente ou com baixo } \\
\text { conteúdo; fitoclastos dominam a assembléia do } \\
\text { querogênio; razão fitoclastos opacos/não-opacos } \\
\text { usualmente baixa; esta fácies pode também ser } \\
\text { dominada por matéria orgânica amorfa parcialmente } \\
\text { oxidada (não-fluorescente) e também por dominada } \\
\text { por fitoclastos não-opacos degradados. }\end{array}$ \\
\hline $\begin{array}{l}\text { CD } \\
\mathrm{IH}=50-125 \\
\mathrm{COT}<0,5 \%\end{array}$ & $\begin{array}{l}\text { Matéria orgânica terrestre moderadamente a bem } \\
\text { oxidada; matéria orgânica residual substancial ou } \\
\text { redepositada. }\end{array}$ & $\begin{array}{l}\text { Matéria orgânica amorfa ausente ou em baixo } \\
\text { conteúdo; fitoclastos dominam a assembléia, razão } \\
\text { de fitoclastos opacos/não-opacos aumenta; esta fácies } \\
\text { pode também ser dominada por matéria orgânica } \\
\text { amorfa parcialmente oxidada (sem fluorescência), e } \\
\text { até também dominada por fitoclastos opacos ou não- } \\
\text { opacos degradados. }\end{array}$ \\
\hline $\begin{aligned} & \text { D } \\
& \mathrm{IH}<50 \\
& \mathrm{COT}<0,5 \%\end{aligned}$ & $\begin{array}{l}\text { Matéria Orgânica residual altamente oxidada ou } \\
\text { redepositada. }\end{array}$ & $\begin{array}{l}\text { Matéria orgânica amorfa ausente ou em baixo } \\
\text { conteúdo; fitoclastos dominam a assembléia; razão de } \\
\text { fitoclastos opacos/ não-opacos aumenta; esta fácies } \\
\text { pode também ser dominada por matéria orgânica } \\
\text { amorfa parcialmente oxidada (sem fluorescência) ou } \\
\text { até mesmo por dominada por fitoclastos opacos. }\end{array}$ \\
\hline
\end{tabular}

proximal flúvio-deltaica a pró-deltaica e fácies de plataforma óxica (C e CD); (c) Fácies de plataforma óxica, distal e lentamente depositada (D).

No limite da fácies anóxica-disóxica, a fácies orgânica BC representa sedimentos com um aporte relativamente elevado de fitoclastos (geralmente nas margens da bacia), enquanto as fácies orgânicas $\mathrm{A}, \mathrm{AB}$ e $\mathrm{B}$ ocorrem onde existe um aporte relativamente baixo de fitoclastos (em função, por exemplo, do clima, do escoamento superficial e da distância de áreas-fonte flúviodeltaicas).
As fácies $\mathrm{A}$ e $\mathrm{AB}$ são diferenciadas pelo o aumento da proporção relativa de matéria orgânica oilprone (e.g. palinofácies com domínio de algas do gênero Tasmanites) e a fácies A geralmente está relacionada a paleoambientes lacustres (e.g. palinofácies com domínio de algas do gênero Botryococcus)

Como exemplo da correlação das técnicas de palinofácies e fácies orgânica sensu Jones, a tabela 6 sumariza as informações relativas a alguns parâmetros de palinofácies, de geoquímica orgânica, e sedimentologia em seções marinhas siliciclásticas (Tyson 1995). 
Tabela 6 - Correlação das técnicas de palinofácies e fácies orgânica sensu Jones (1987) utilizando alguns parâmetros de palinofácies, de geoquímica orgânica, e sedimentologia em seções marinhas siliciclásticas (Tyson 1995).

\begin{tabular}{|c|c|c|c|c|c|c|c|}
\hline $\begin{array}{l}\text { Fácies Orgânica } \\
\text { Palinofácies }\end{array}$ & $\mathbf{A}$ & $\mathbf{A B}$ & B & BC & C & CD & D \\
\hline $\begin{array}{c}\% M O A \text { do total do } \\
\text { querogênio }\end{array}$ & \multicolumn{3}{|c|}{ dominante } & moderada & \multicolumn{3}{|c|}{ usualmente baixa/ausente } \\
\hline Fluorescência da MOA & \multicolumn{2}{|c|}{ intensa } & \multicolumn{2}{|c|}{ moderada a fraca } & fraca & \multicolumn{2}{|c|}{ usualmente ausente } \\
\hline $\begin{array}{c}\% \text { Fitoclasto do total do } \\
\text { querogênio }\end{array}$ & \multicolumn{3}{|c|}{ baixa (diluição) } & moderada & \multicolumn{3}{|c|}{ usualmente dominante } \\
\hline $\begin{array}{c}\text { Razão Fitoclasto Opaco/ } \\
\text { Não-opaco }\end{array}$ & \multicolumn{3}{|c|}{ geralmente alta } & \multicolumn{2}{|c|}{ usualmente baixa } & \multicolumn{2}{|c|}{ aumenta } \\
\hline $\begin{array}{l}\quad \underline{\text { Fácies Orgânica }} \\
\text { Geoquímica }\end{array}$ & $\mathbf{A}$ & $\mathbf{A B}$ & B & BC & C & CD & D \\
\hline Índice de Hidrogênio & $\geq 850$ & $\geq 650$ & $\geq 400$ & $\geq 250$ & $\geq 125$ & $50-125$ & $\leq 50$ \\
\hline Tipo de Querogênio & I & $\mathrm{I} / \mathrm{II}$ & II & $\mathrm{II} / \mathrm{III}$ & III & III/IV & IV \\
\hline$\% C O T$ & $5-20^{+}$ & \multicolumn{2}{|c|}{$3-10^{+}$} & $3-3^{+}$ & $\leq 3$ & \multicolumn{2}{|c|}{$<0,5$} \\
\hline $\begin{array}{l}\underline{\text { Fácies Orgânica }} \\
\underline{\text { Fatores }} \\
\underline{\text { Ambientais }}\end{array}$ & $\mathbf{A}$ & $\mathbf{A B}$ & B & BC & $\mathrm{C}$ & CD & D \\
\hline Tendência proximal-distal & \multicolumn{3}{|c|}{ distal } & \multicolumn{4}{|c|}{ proximal / distal } \\
\hline Regime de Oxigênio & anóxico & \multicolumn{3}{|c|}{ anóxico - disóxico } & \multicolumn{2}{|c|}{ óxico } & muito óxico \\
\hline $\begin{array}{l}\text { Taxa de acumulação } \\
\text { sedimentar }\end{array}$ & baixa & \multicolumn{2}{|c|}{ várias } & \multicolumn{2}{|c|}{ alta } & moderada & baixa \\
\hline Fácies Orgânica & $\mathbf{A}$ & $\mathbf{A B}$ & B & BC & C & CD & D \\
\hline
\end{tabular}

Associado a esta chave de classificação, o emprego dos campos de palinofácies marinhas de Tyson (1993) tem contribuído para uma melhor caracterização da faciologia orgânica em seções sedimentares geradoras de petróleo e na identificação de fácies orgânicas em rochas reservatório e selante (Fig. 4).

\section{EXEMPLOS EM SEÇÕES SEDIMENTARES}

Paleozóico No Brasil, Mendonça Filho (1999) foi pioneiro na aplicação da Palinofácies associada a Geoquímica Orgânica. Em seu trabalho, o autor utilizou a faciologia orgânica no estudo da seqüência permiana da Bacia do Paraná no Estado do Rio Grande do Sul e demonstrou que a sucessão de parâmetros obtidos mostrou-se eficiente na determinação da extensão das mudanças paleoambientais. As variações palinofaciológicas refletiram importantes mudanças tanto na po- laridade deposicional dos sedimentos (tendência proximal-distal), quanto no estado de preservação da matéria orgânica (Fig. 5).

Souza (2007) utilizou a palinofácies e a fácies orgânica (sensu Jones) para estudar amostras da Formação Pimenteira coletadas em dois poços da borda leste da Bacia do Parnaíba, com o intuito de fornecer dados sobre o paleoambiente deposicional e avaliar a potencialidade de geração de petróleo nesta área da bacia. A partir da correlação dos dados, o autor identificou uma grande influência deltaica nas condições deposicionais e um baixo potencial gerador de hidrocarbonetos. Além disso, foi possível mapear tendências regressivas e transgressivas em fácies sedimentares uniformes (siltitos e folhelhos), a partir do decréscimo ou incremento no conteúdo de palinomorfos marinhos, COT e IH (Fig. 6). 


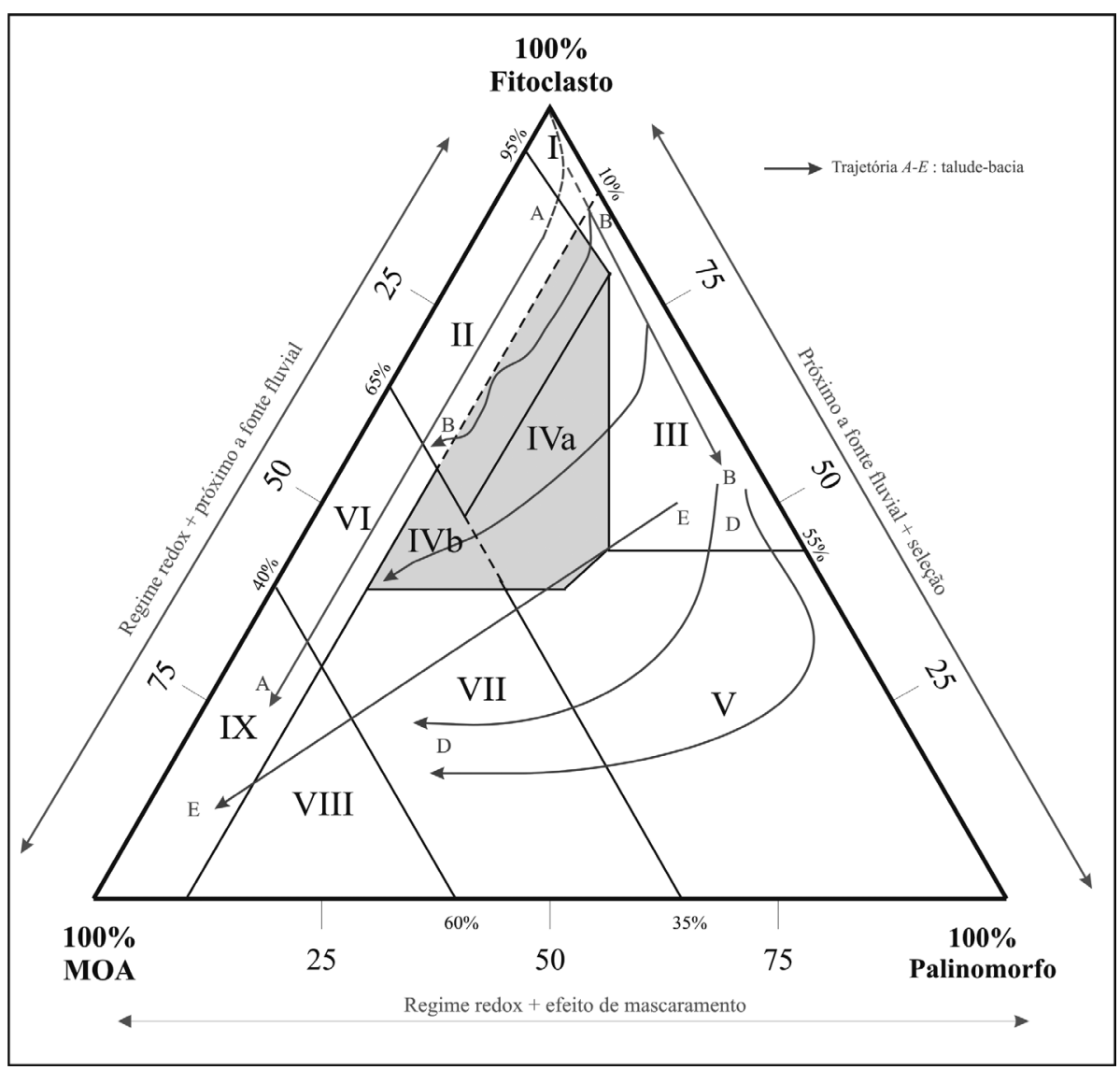

\begin{tabular}{|c|c|}
\hline $\begin{array}{l}\text { CAMPOS DE } \\
\text { PALINOFÁCIES }\end{array}$ & CARACTERÍSTICAS DEPOSICIONAIS DA MATÉRIA ORGÂNICA \\
\hline I & $\begin{array}{l}\text { Bacia ou plataforma altamente proximal } \\
\text { Alto suprimento de fitoclastos dilui todos os outros componentes. }\end{array}$ \\
\hline II & $\begin{array}{l}\text { Bacia marginal disóxica-anóxica } \\
\text { MOA diluida pelo alto suprimento de fitoclastos, mas com moderada a boa preservação. } \\
\text { Quantidade de COT marinho depende do estado redox da bacia. }\end{array}$ \\
\hline III & $\begin{array}{l}\text { Plataforma óxica heterolítica ("plataforma proximal") } \\
\text { Geralmente baixa taxa de preservação de MOA, abundância absoluta de fitoclastos } \\
\text { depende da proximidade de fontes flúvio-deltaicas. Oxidação e retrabalhamento comuns. }\end{array}$ \\
\hline IV & $\begin{array}{l}\text { Transição plataforma-bacia } \\
\text { Transição plataforma-bacia no tempo (e.g. aumento da subsidência/profundidade da lâmina d'água) ou espaço (talude). } \\
\text { Abundância absoluta de fitoclastos depende da proximidade da fonte fluvial e do grau de redeposição. Quantidade de COT } \\
\text { marinho depende do estado redox da bacia. } \\
\text { IVa: disóxico. IVb: subóxico-anóxico. }\end{array}$ \\
\hline V & $\begin{array}{l}\text { Plataforma óxica dominada por lama ("plataforma distal") } \\
\text { Baixa a moderada MOA (geralmente degradada). Palinomorfos abundantes. } \\
\text { Margas de coloração clara, bioturbadas são comuns. }\end{array}$ \\
\hline VI & $\begin{array}{c}\text { Plataforma proximal subóxica-anóxica } \\
\text { Boa taxa de preservação de MOA, bacia apresenta condições redutoras. Conteúdo } \\
\text { absoluto de fitoclastos deve ser moderado a alto, devido ao input de turbiditos e/ou } \\
\text { proximidade da fonte flúvio-deltaica. }\end{array}$ \\
\hline VII & $\begin{array}{c}\text { "Plataforma" distal disóxica-anóxica } \\
\text { Moderada a boa taxa de preservação de MOA, baixo a moderado conteúdo de } \\
\text { palinomorfos. Lamitos escuros bioturbados são comuns. }\end{array}$ \\
\hline VIII & $\begin{array}{c}\text { Plataforma distal disóxica-óxica } \\
\text { MOA dominante, excelente taxa de preservação. Baixo a moderado conteúdo de } \\
\text { palinomorfos. Folhelhos ricos em matéria orgânica são depositados sob condições } \\
\text { de coluna d'água estratificada. }\end{array}$ \\
\hline XI & $\begin{array}{c}\text { Bacia distal subóxica-anóxica/Plataforma carbonática/Marinho Restrito } \\
\text { MOA dominante. Baixo conteúdo de palinomorfos. Freqüentemente rico em alginitas. } \\
\text { Depósitos de águas profundas ou depósitos de condições de coluna d'água } \\
\text { estratificada ou sedimentos de bacia faminta. }\end{array}$ \\
\hline
\end{tabular}

Figura 4 - Diagrama ternário Fitoclasto-MOA-Palinomorfo utilizado na definição de palinofácies em seções marinhas com os respectivos campos de paleoambiente correspondentes à deposição de matéria orgânica (modificado de Tyson, 1993, 1995). 


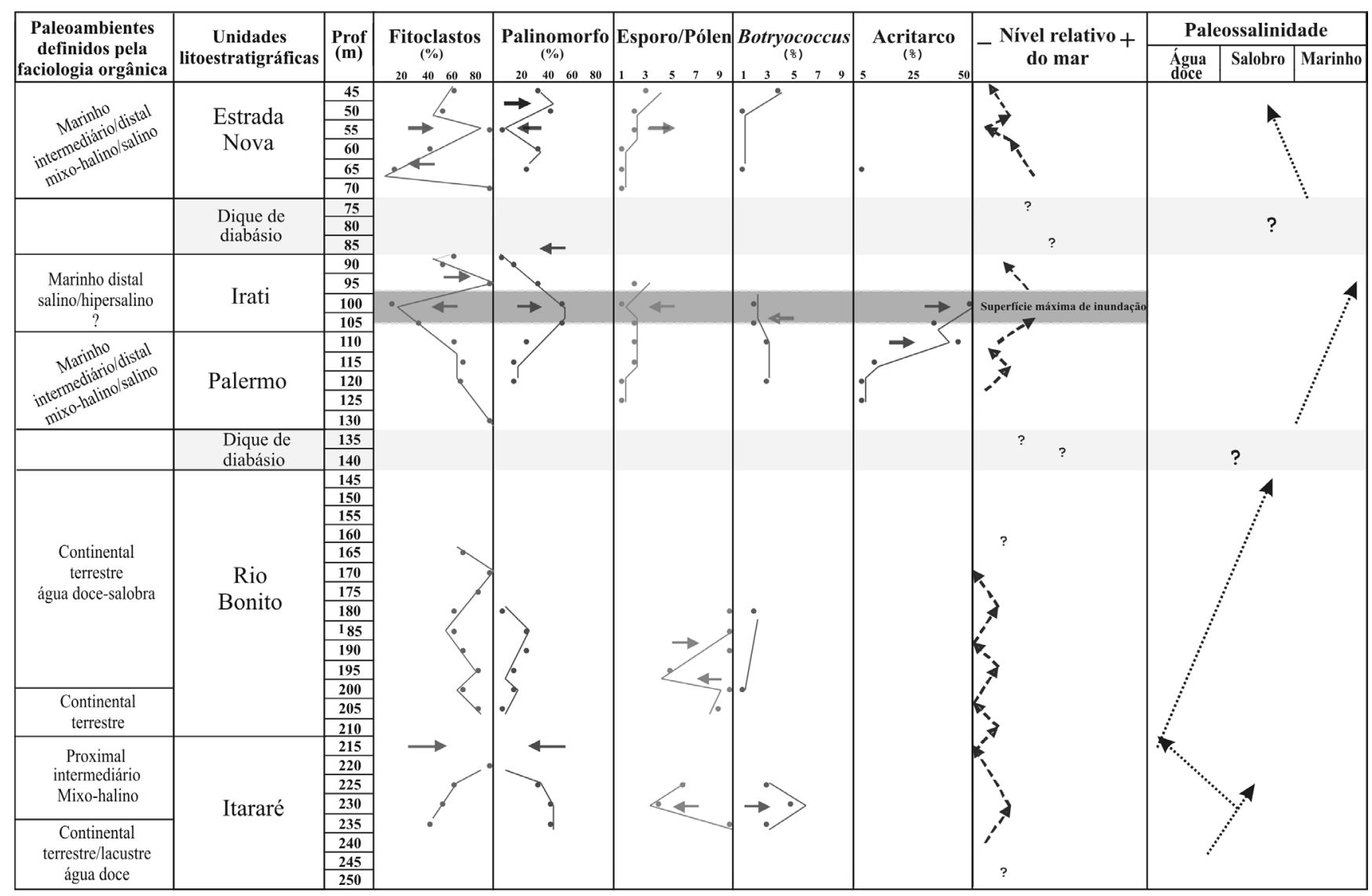

Figura 5 - Variações de paleoambiente, paleossalinidade e nivel relativo do mar de acordo com os dados de faciologia orgânica para as unidades litoestratigráficas da sondagem 5-TG-96-RS (Mendonça Filho, 1999).

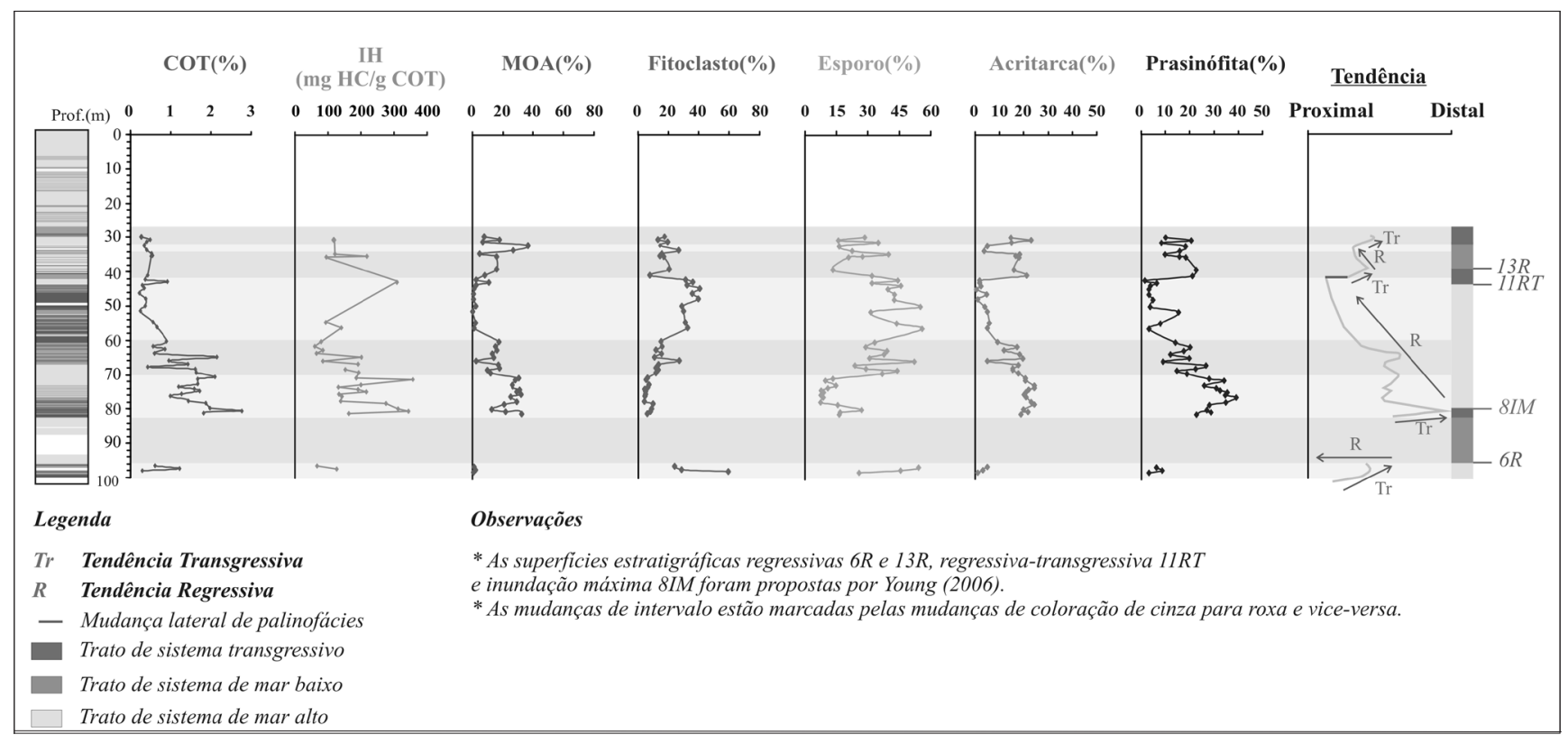

Figura 6 - Correlação entre os resultados de palinofácies, COT e IH utilizados na elaboração da curva de tendência deposicional do testemunho PM-10 (Souza, 2007).

Mesozóico Carvalho (2001) caracterizou intervalos baseados na abundância relativa da matéria orgânica particulada em uma seção sedimentar aptiana-albiana da Bacia de Sergipe que permitiram um melhor entendimento da evolução paleoambiental da bacia. Esses intervalos registraram mudanças palinofaciólogicas 
controladas pelas variações do nível relativo do mar durante a deposição da Formação Muribeca (fase transicional) a implantação de condições progressivamente transgressivas para o topo da seção (Formação Riachuelo) (Fig. 7).

Iemini et al. (2007) estudaram amostras da Formação La Luna (Seção Riacho Bambuca, Colômbia) e, de acordo com a correlação dos resultados de palinofácies com COT e IH, a deposição ocorreu predominantemente em um paleoambiente de bacia distal sob um regime subóxico-anóxico. Contudo, devido a oscilações do nível relativo do mar houve também a deposição de fácies orgânica característica de plataforma distal disóxica-óxica. Tais condições no paleoambiente favoreceram uma elevada produtividade primária e posterior intenso retrabalhamento microbiológico sob coluna d'água anóxica persistente que propiciou a formação de depósitos ricos em matéria orgânica de excelente qualidade para geração de hidrocarbonetos.

Cenozóico Menezes (2002) caracterizou o predomínio dos tecidos cuticulares em sedimentos pleistocêni- cos do talude continental da Bacia de Campos e verificou o controle dos processos deposicionais que atuaram na distribuição desses componentes que possuem tendências de deposição em fácies proximais. Além disso, a partir das associações palinofaciólogicas foi possível identificar intervalos de maior e menor influência de aporte de material orgânico de origem continental relacionados às oscilações do nível relativo do mar, reflexo de flutuações climáticas, ocorridas nos últimos 150.000 anos AP, que influenciaram no suprimento de material orgânico, uma vez que interferiram principalmente na paleoceanografia da região analisada (Fig. 8).

Menezes et al. (2005) observaram a correlação positiva entre os teores mais elevados de COT com o domínio de uma palinofácies marinha rica em fitoclastos opacos (matéria orgânica refratária) em duas seções sedimentares terciárias da Bacia de Jequitinhonha. Neste caso ressalta-se a importância da caracterização da matéria orgânica particulada, pois incrementos nos teores de COT não necessariamente estão associados a uma fácies orgânica oil-prone (Fig. 9).

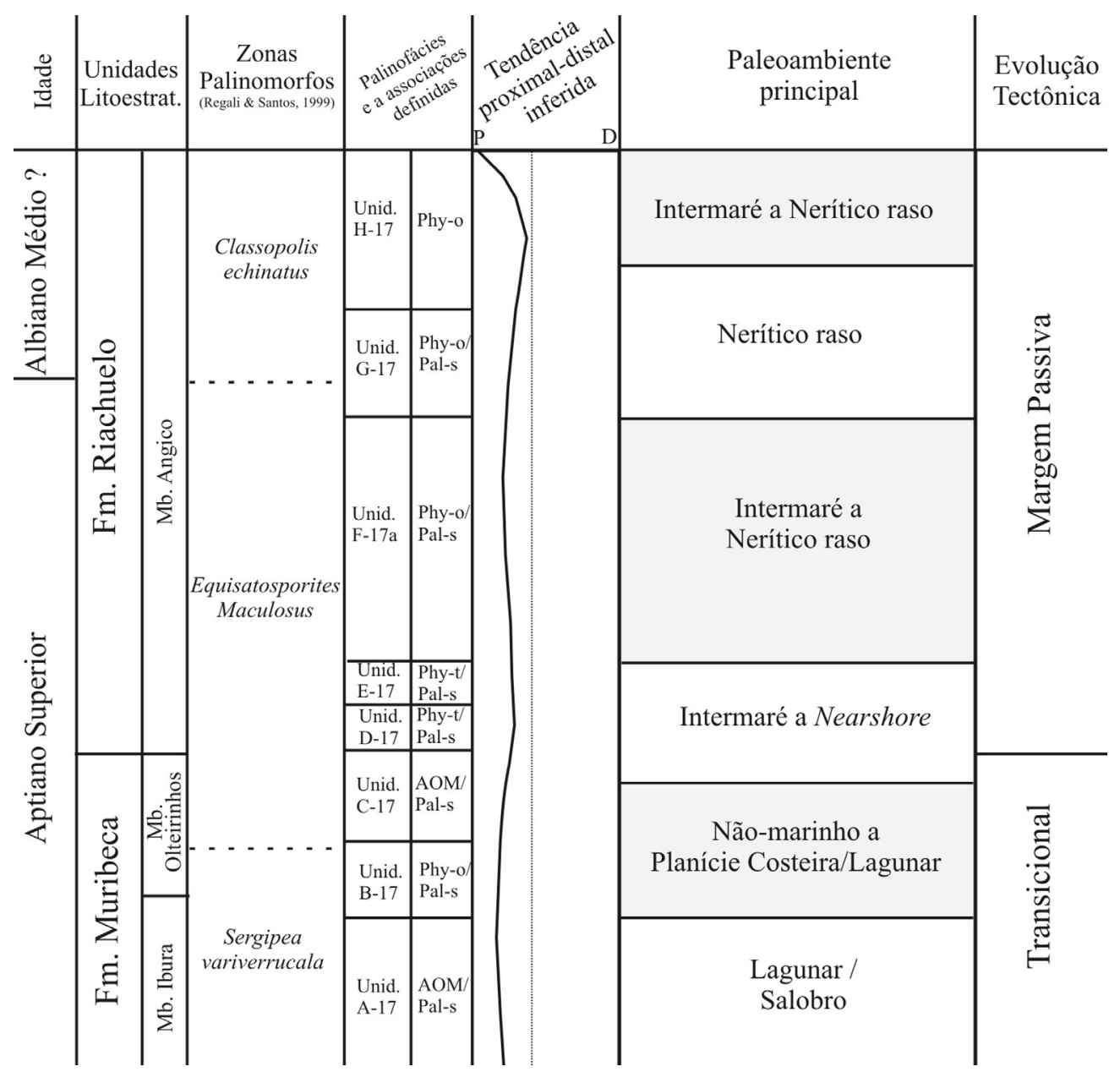

Figura 7 - Interpretação paleoambiental a partir da correlação dos parâmetros do poço GTP-17-SE (Carvalho, 2001). 


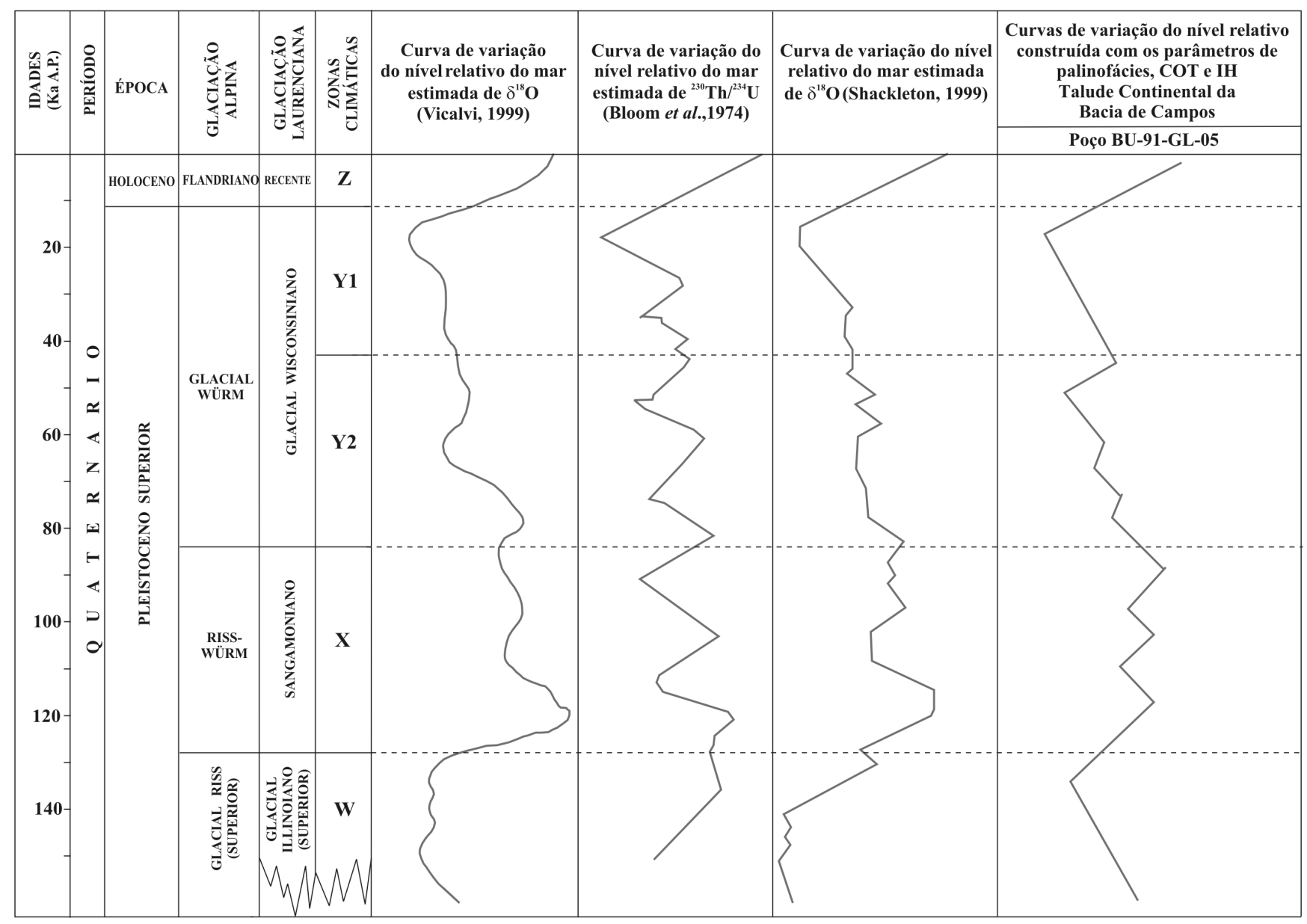

Figura 8 - Correlação gráfica das tendências de variação eustática do nível relativo do mar no Quaternário entre curvas fornecidas por diferentes autores e resultados obtidos com os dados palinofaciológicos e organogeoquímicos no talude continental da Bacia de Campos (Menezes, 2002).

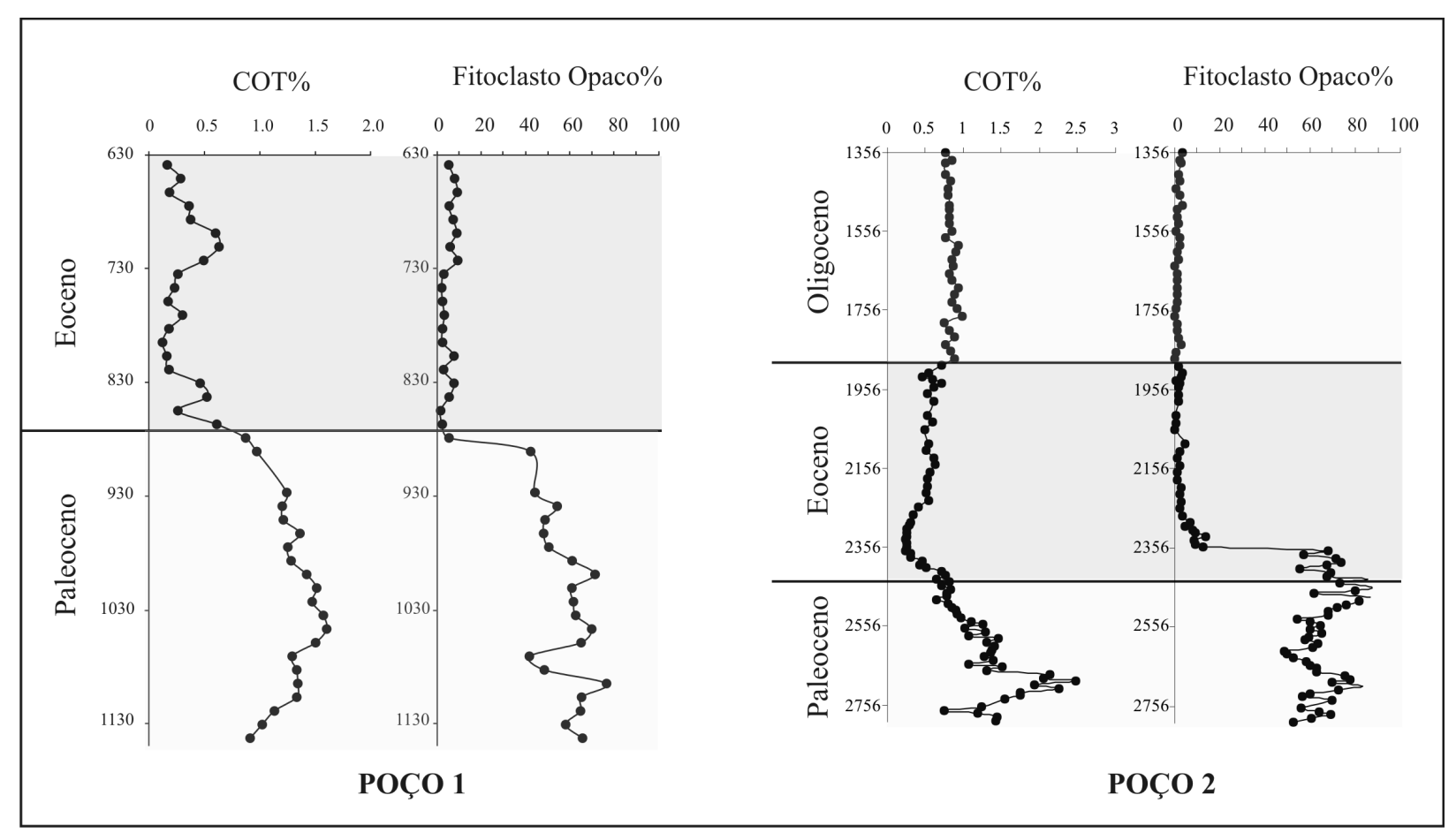

Figura 9 - Gráfico de correlação COT x fitoclasto opaco exibindo o controle da matéria orgânica refratária no teor de COT (Menezes et al., 2005). 
CONCLUSÕES Os estudos de casos abordados nesse trabalho revelaram que é possível aplicar o método de fácies orgânica em diversos períodos geológicos, sendo possível subdividir fácies sedimentares uniformes, determinar a magnitude e localização do aporte terrestre e identificar as tendências regressivas-transgressivas no contexto da Estratigrafia de Seqüências.
Além disso, essa ferramenta assumiu um papel importante tanto na caracterização do potencial de geração de hidrocarbonetos de uma rocha, quanto na caracterização paleoambiental e deposicional de pacotes sedimentares auxiliando, desta forma, na identificação dos elementos essenciais de um sistema petrolífero.

\section{Referências}

Al-Ameri T.K., Al-Najar T.K., Batten D.J., 2001. Palynostratigraphy and palynofacies indications of depositional environments and source potential for hydrocarbons: the mid Cretaceous Nahr Umr and lower Mauddud formations Iraq. Cretaceous Research, 22(6):735-742.

Al-Ameri T.K., Al-Musawi F.S., Batten D.J. 1999. Palynofacies indications of depositional environments and source potential for hydrocarbons: uppermost Jurassic-basal Cretaceous Sulaiy Formation,southern Iraq. Cretaceous Research, 20(3):359-363.

Araujo C.V., Condé V., Botelho Neto J., Pedrão. E., Conceição J.C. 1998. Palynofacies in a Sequence Stratigraphy Context: an Example of an Upper Aptian Section from Almada Basin, Brazil. In: Mello M.R. \& Yilmaz P.O. (eds.) AAPG International Conference and Exhibition Extented Abstracts, p. 582-583.

Batten D.J. 1996. Palynofacies and palaeoenvironmental interpretation. In: Jansonius J. \& McGregor D.C. (eds.) Palynology: principles and applications volume 3, p. 1011-1064.

Batten D.J. 1982a. Palynofacies and salinity in the Purbeck and Wealden of southern England. In: Banner F.T. \& Lord A.R. (eds.) Aspects of Micropalaeontology, p. 278308.

Batten D.J. 1982b. Palynofacies, palaeoenvironments and petroleum. Journal of Micropalaeontology, 1:107-114.

Batten, D.J. 1983. Identification of amorphous sedimentary organic matter by transmitted light microscopy. In: Brooks J. (ed.) Petroleum geochemistry and exploration of Europe. Oxford, Blackwell, p. 275-287.

Baudin F., Tribovillard N., Laggoun-Défarge F., Lichtfouse E., Monod O., Gardin S. 1999. Depositional environment of a Kimmeridgian carbonate 'black band' (Akkuyu Formation, south-western Turkey). Sedimentology, 46:589-602.

Carvalho M.A. 2001. Paleoenvironmental reconstruction based on palynology and palynofacies analyses of Upper Aptian-Middle Albian sucession from Segipe Basin, northeaster Brazil. Tese de Doutoramento, RuprechtKarl Heidelberg, Alemanha, 160p.

Chow N., Wendte J., Stasiuk L.D. 1995. Productivity versus preservation controls on two organic-rich carbonate facies in the Devonian of Alberta: sedimentological and organic petrological evidence. Bulletin of Canadian Petroleum Geology, 43:433-460.

Combaz A. 1964. Les palynofacies. Revue de Micropaléontologie, 7:205-218.

Cornford C. 1979. Organic deposition at a Continental Rise: Organic geochemical interpretation and synthesis at
DSDP Site 397, Eastern North Atlantic. In: von Rad U., Ryan W.B.F., Arthur M.A., Cepek P., Cita M.B., Cornford C., Garifal L., Hamilton N., Lopatin B., Lutze G.F., McCoy F.W., Mountain G., Sarnthein M., Weser O.E., Whelan J.K., Wind F.H. (eds.) Initial Reports of the Deep Sea Drilling Project. Part. 1: Washington (U.S. Government Printing Office), v. 47, p. 503-510.

Cornford C., Rüllkötter J., Welte D. 1980. A synthesis of organic petrographic and geochemical results from DSDP sites in the eastern central North Atlantic. Phys. Chem. Earth, 12:445-453.

Correia M. 1967. Relations possibles entre l'état de conservation des éléments figurés de la matière organique et l'existence de gisements d'hydrocarbures. Oil \& Gas Science and Technology, 22:1285-1306.

Demaison G., Huizinga B.J. 1991. Genetic classification of petroleum systems. AAPG Bulletin, 75:1623-1643.

Didyk B.M., Simoneit B.R.T., Brassell S.C., Eglinton G. 1978. Nature, 272:216-222.

Dow W.G. 1977. Kerogen studies and geological interpretation. Journal of Geochemical Exploration, 7:79-99.

Durand B. 2003 . A History of Organic Geochemistry. Rev. IFP.- Oil \& Gas Science and Technology, 58(2):203231.

Durand B. 1980. Sedimentary organic matter and kerogen. Definition and quantitative importance of kerogen, In: Durand B. (ed.) Kerogen: Insoluble Organic Matter from Sedimentary Rocks. Editions technip, Paris, p. 13-34.

Espitalié J., Madec M., Tissot B., Mennig J.J., Leplat P. 1977. Source rock characterization method for petroleum exploration. In: Annual Offshore Techn. Conference, $9^{\text {th }}$, Proceedings, p. 439-444.

Follows B. \& Tyson R.V. 1998. Organic facies of the Asbian (early Carboniferous) Queensferry Beds, Lower Oil Shale Group, South Queensferry, Scotland, and a brief comparison with other Carboniferous North Atlantic oil shale deposits. Organic Geochemistry, 29(4): 821-844.

Gonçalves F.T.T., Araújo C.V., Penteado H.L.B., Hamsi Jr., G.P., Frota E.S.T., Soldan A.L. 1997. Séries Naturais: Aplicação No estudo dageração e expulsão do petróleo e no mapeamento de oil-kitchens. B. Geoci. PETROBRAS, Rio de Janeiro, 11(1/2):116-131.

Gorin G.E. \& Steffen D. 1991. Organic facies as a tool for recording eustatic variations in marine fine-grained carbonates - example of the Berriasian stratotype at Berrias (Ardrche, Southeast France). Palaeogeogr.Palaeoclimatol. Palaeoecol. 85:303-320

Gutjahr C.C.M. 1966. Carbonisation Measurements of Pollen Grains and Spores and their Application. Leidse Geolog. 
Mededel, 38:1-29.

Habib D. 1982. Sedimentary supply origin of cretaceous black shales, In: Schlanger S.O \& Cita M.B. (eds.) Nature and origin of Cretaceous Carbon-rich Facies. London, Academic Press, p.113-27.

Huc A.Y. 1990. Understanding Organic Facies: A Key to Improved Quantitative Petroleum Evaluation of Sedimentary Basins. In: Huc A.Y. (ed.) Deposition of Organic Facies. Oklahoma, AAPG Studies in Geology, 30:1-11.

Hughes N.F. \& Moody-Stuart J.C. 1967. Palynological facies and correlation in Wealden. Review of Palaeobotany and Palynology, 1:259-268.

Iemini J.A., Mendonça Filho J.G., Goncalves F.T.T., Menezes T.R. 2007. Fácies Orgânica da Formação La Luna, Bacia do Valle Superior del Magdalena, Colômbia: Implicações para geração de petróleo e caracterização paleoambiental. Anuário do Instituto de Geociências UFRJ, 30(2):65-81.

Jacobson S.R. 1991. Petroleum source rocks and organic facies. In: Merril R.K. (ed.) Source and Migration Processes and Evaluation techniques. Treatise of Petroleum Geology, American Association of Petroleum Geologists, Tulsa, p. 3-11.

Jones R.W. 1987. Organic facies. In: Brooks J. \& Welte D. (eds.) Advances in Petroleum Geochemistry. London, Academic Press, p. 1-90.

Jones R.W. \& Demaison G.J. 1982. Organic facies - stratigraphic concept and exploration tool. In: Salvidar-Sali A. (ed.) Proceedings of the Second ASCOPE Conference and Exhibition, p. 51-68.

Jones R.W. \& Demaison G.J. 1980. Organic Facies-Stratigraphic Concept and Exploration Tool. AAPG Bulletin, 64(5):729.

Jones R.W \& Edison T.A. 1979. Integration of Microscopic Organic Analysis and Geochemical Measurements in Evaluation of Source Rocks. AAPG Bulletin, 63(3):476.

Jones R.W. 1978. Som Mass Balance and Geological Restraints on Migration Mechanismos. AAPG Special Volumes, 8:1-43.

Lallier-Vergés E., Bertrand P., Huc A.Y., Buckel D., Tremblay P. 1993. Control on the preservation of organic matter by productivity and sulphate reduction in Kimmeridge shales from Dorset (UK). Marine and Petroleum Geology, 10:600-605.

Magoon L.B. \& Dow W.G. 2000. Mapping the petroleum system - An Investigative technique to explore the hydrocarbon fluid system. In: Mello M.R. \& Kats B.J. (eds.) Petroleum systems of South Atlantic Margins. AAPG Memoir 73:53-68.

Mendonça Filho J.G., Menezes T.R., Oliveira A.D., Mendonça J.O. 2007. Aplicação da Palinofácies na Exploração Petrolifera. In: Congresso Brasileiro de Geoquímica, 11, Atibaia, Anais, CDRom.

Mendonça Filho J.G. 1999. Aplicação de estudos de palinofácies e fácies orgânicas em rochas do Paleozóico Superior da Bacia do Paraná, sul do Brasil. Tese de Doutoramento, Universidade Federal do Rio Grande do Sul, 254 p.

Mendonça Filho J.G., Carvalho M. A., Menezes T. R. 2002. Palinofácies. In: Dutra T.L. (ed.) Técnicas e Procedi- mentos para o Trabalho com Fósseis e Formas Modernas Comparativas. Unisinos, 1:20-24.

Menezes T.R., Araujo C.V., Strohschoen Junior O., Lana C.C., Maizatto J.R. 2005. Relationship between TOC contents and palynofacies distribution of a paleogene section from Jequitinhonha basin, Brazil. In: International Meeting on Organic Geochemistry, Sevilha, 1:298-299.

Menezes T.R. 2002. Aplicação de parâmetros palinofaciológicos e organogeoquímicos na reconstrução paleoambiental do talude continental brasileiro recente na Bacia de Campos, RJ. Dissertação de Mestrado, Universidade Federal do Rio de Janeiro, Rio de Janeiro p.174.

Oboh F.E. 1992. Middle Miocene palaeoenvironments of the Niger Delta. Palaeogeography, Palaeoclimatology, Palaeoecology, 92:55-84.

Oboh-Ikuenobe F.E., Obi C.G., Jaramillo C.A. 2005. Lithofacies, palynofacies, and sequence stratigraphy of Palaeogene strata in Southeastern Nigeria. Journal of African Earth Sciences, 41:79-101.

Oliveira A.D., Mendonca Filho J.G., Sant'Anna A.J., Souza J.T., Freitas A.G., Menezes T. R. 2006. Inovação no processamento químico para isolamento da Matéria Orgânica Sedimentar. In: SBG/Núcleo Bahia-Sergipe, Congresso Brasileiro de Geologia, 43, Aracaju, Anais, p. 324.

Oliveira A.D., Mendonça Filho J.G., Carvalho M. A., Menezes T.R., Lana C.C., Brenner WW. 2004. Novo método de preparação palinológica para aumentar a recuperação de Dinoflagelados. Revista Brasileira de Paleontologia, 7(2):169-175.

Pasley M.A. 1991. Organic matter variation within depositional sequences stratigraphic significance of implication to petroleum source rock prediction. The Lousiana State,University and agricullural and Mechanical Col. Lousiana (USA). PhD. Thesis, 150p.

Penteado H.L.B. \& Behar F. 2000. Geochemical characterization and compositional evolution of the Gomo Member source rocks in the Recôncavo Basin (Brazil). In: Mello M.R. \& Katz B.J. (eds.) Petroleum systems of South Atlantic Margins. AAPG Memoir 73:179-194.

Peters K.E. \& Cassa M.R. 1994. Applied source rock geochemistry. In: Magoon L.B. \& Dow W.G. (eds.) The Petroleum System - from Source to Trap. AAPG Memoir, 60:93-120.

Peters K.E., Rohrback B.G., Kaplan I.R. 1981. Geochemistry of artificially heated humic and sapropelic sediments - 1: protokerogen. AAPG Bulletin, 65:688-705

Powell T.G. 1987. Depositional controls on source rocks character and crude oil composition. In: World Petroleum Congress, $12^{\text {th }}$, Houston, 2, Proccedings, p.31-42.

Quadros L.P. 1975. Organopalinologia na prospecção de petróleo. Boletim Técnico da Petrobras., 18(1):3-11.

Rogers M.A. 1980. Application of organic facies concepts to hydrocarbon source-rock-evaluation. In: World Petroleum Congress, 10, Proceedings, 10:23-30.

Rogers M.A. \& Koons C.B. 1971. Origin and Refining of Petroleum. Advances in Geochemistry Series. Am. Chem. Soc., 103:67-80.

Rudkiewicz J.L., Penteado H.L.B., Vear A., Vandenbroucke M., Brigaud F., Wendebourg J., Düppenbecker S. 2000. Integrated basin modeling helps to decipher petroleum 
systems. In: Mello M.R. \& Kats B.J. (eds.) Petroleum systems of South Atlantic Margins. AAPG Memoir 73:27-40.

Schiǿler P., Crampton J.S., Laird M.G. 2002. Palynofacies and sea-level changes in the Middle Coniacian-Late Campanian (Late Cretaceous) of the East Coast Basin, New Zealand. Palaeogeography, Palaeoclimatology, Palaeoecology, 188:101-125.

Souto Filho A.C.F., Correa E.V., Santos Neto faltou iniciais, Trindade L.A.F. 2000. Alagamar-Açu petroleum system, onshore Potiguar Basin, Brazil: a numerical approach for secondary migration. In: Mello M.R. \& Kats B.J. (eds.) Petroleum systems of South Atlantic Margins. AAPG Memoir, 73:151-158.

Souza I.V.A.F. 2007. Faciologia Orgânica de uma Seção Devoniana da Bacia do Parnaíba (Formação Pimenteira): Implicações para a Geração de Petróleo. Dissertação de Mestrado, Universidade Federal do Rio de Janeiro, Rio de Janeiro, $160 \mathrm{p}$.

Spigolon A.L.D. 2003. Palinofácies e faciologia orgânica da Formação Alagamar (Aptiano da bacia Potiguar, Brasil): paleoambiente e maturação térmica. Dissertação de Mestrado, Universidade de Brasília, Brasília, p.156.

Stasiuk L.D. \& Fowler M.G. 2004. Organic facies in Devonian and Mississippian strata of Western Canada Sedimentary Basin: relation to kerogen type, paleoenvironment, and paleogeography. Bulletin of Canadian Petroleum Geology, 52(3):234-255.

Stasiuk L.D. 1996. Organic facies in black shale of Devonian-Mississippian Bakken Formation, southeastern Saskatchewan. Canadá, Geological Survey of Canada, Current Research, 1996-B:15-22.

Stasiuk L.D. 1999. Microscopic studies of sedimentary organic matter: key to understanding organic-rich strata, with Paleozoic examples from Western Canada. Geoscience Canada, 26:149-172.

Tissot B.P, Durand B., Espitalié J., Combaz A. 1974. Influence of nature and diagenesis of organic matter in formation of petroleum. American Association of Petroleum Geologists Bulletin, 58:499-506.

Tissot B.P. \& Welte D.H. 1984. Petroleum Formation and Occurrence. Berlin, Springer-Verlag, 699p.
Trindade L.A.F., Penteado H.L.B. 2004. The Role of Petroleum Geochemistry for the Evaluation of Petroleum Systems in Deepwater. AAPG Bulletin, 88, Program Abstracts. Disponível em: http://www.aapg.org/datasystems/. Acesso em 29/11/2007.

Turnau E. \& Racki G. 1999. Givetian palynostratigraphy and palynofacies: new data from the Bodzentyn Syncline (Holy Cross Mountains, central Poland). Review of Palaeobotany and Palynology, 106:237-271.

Tuweni A.O. \& Tyson R.V. (1994) Organic facies variations in the Westbury Formation (Rhaetic, Bristol Channel, SW England). Organic Geochemistry, 21:1001-1014.

Tyson R.V. 1995 . Sedimentary Organic Matter. Londres, Chap. \& Hall, 615 p.

Tyson R.V. 1993. Palynofacies Analysis. In: Jenkins D.J. (eds.) Applied Micropaleontoly. Kluwer Academic Publishers, Dordrecht. p. 153-191.

Tyson R.V. 1987. The genesis and palynofacies characteristics of marine petroleum source rocks. In: Brooks J. \& Fleet A.J. (eds.) Marine petroleum source rocks. Oxford, Geological Society Special Publication, Blackwell Scientific Publications, 26:47-68.

Tyson R.V. 1984. Palynofacies investigation of Callovian (Middle Jurassic) sediments from DSDP Site 534, Blake-Bahama Basin, western Central Atlantic. Marine and Petroleum Geology, 1:3-13.

Van Krevelen D.W. 1961. Coal: Typology-Chemistry-Physics-Constitution. Amsterdam, Elsevier, 514p.

Waples D.W.1994. Modeling of Sedimentary Basins and Petroleum Systems. In: Maggon L.B. \& Dow W.G. (eds.) The petroleum system - from source to trap. AAPG Memoir, 60:307-322.

Zavattieri A.M., Rosenfeld U., Volkheimer W. 2008. Palynofacies analysis and sedimentary environment of Early Jurassic coastal sediments at the southern border of the Neuquén Basin, Argentina. Journal of South American Earth Sciences, 25:227-245.

Manuscrito BR 21

Submetido em 19 de dezembro de 2007 Aceito em 18 de maio de 2008 